\title{
Language and power: Korean-Chinese students' language attitude and practice
}

Dr. F. GAO ${ }^{1}$

Faculty of Education, University of Hong Kong

Postal address:

Rm420, 4/F, Hui Oi Chow Science Building

Faculty of Education, HKU

Pokfulam Road, Hong Kong

Email: gaofang@graduate.hku.hk

\footnotetext{
${ }^{1}$ Email: gaofang@graduate.hku.hk
} 


\section{Language and power: Korean-Chinese students' language attitude and practice}

Language is not only a method of communication, but also a mechanism of power. The ethnographic research reported in this article documents how a group of Korean students, who are participating in a bilingual Korean school in Northeast China, construct their language attitude and practice. Research findings indicate that the Korean students value both Korean and Chinese language acquisition, and adopt the two languages for self-empowerment in the academic hierarchy of the Korean school. The positive attitude and practice of Korean students toward Korean and Chinese language studies highlight the politically and economically functional power of Korean and Chinese languages as a means of acquiring a larger benefit from China's economic marketization, especially increasing business contacts with South Korea. This article argues that the increasing significance of transnationalism for ethnic minorities within globalization emphasizes bilingual proficiency, or even trilingualism in China's reform period which implies the necessity of relevant policy initiations for the increasing needs of language acquisition.

Keywords: language and power; Korean language; Chinese language; language attitude and practice, bilingualism, transnationalism

(Number: 5467) 


\section{Introduction: Language and power}

The role of linguistic rights in the construction of minorities has captured theorists' attention, which currently examines questions of linguistic policy and their relevance to broader issues of democracy, justice, rights, and education (Kymlicka and Patten 2003; May 2003). Language is not only a method of communication, but also a mechanism of power (Bourdieu 1991). It is critical in the formation of social groups and struggles for power and prestige among groups. Language discourse is not simply about language, but is equally about much wider social processes and practices (Foucault 1980). The decision of which language(s) to act as the official or dominant language is dependent upon the power of dominant group(s), more or less at the expense of the rights of the dominated groups. The devaluing of other languages reflects the real power of language which clearly lies in the dominant or official languages. This has meant that avenues for personal development and upward social mobility among minorities are virtually restricted (Tollefson 1990).

Within globalization, however, it is most likely that every individual operates in a multilingual environment. To some extent, the use of non-dominant language becomes an integral part of the empowerment process. Fei Xiaotong's (1991) 'duoyuan yiti geju' which has been translated by (Postiglione 2007) into 'plurality within the organic unity of the Chinese nationality' with its functionalistic value highlights the national unification and cultural pluralism of China. China's Constitution maintains the equal status of ethnic minorities and their right to preserve and develop own languages and customs (Iredale et 
al. 2001). In nation-state building, language is a political power which serves the goals of building the nation-state (Zhou 2005). This includes taking a legislative approach to literacy development for ethnic minorities. Literacy in official language is prompted by a political and economic power since the early years of the People's Republic of China (PRC) (Hayford 1987). Rather, literacy in some minority languages such as Korean language both prior to and after China's reform period has also achieved both economic and political powers. Ethnic Koreans in China have had a politically strategic importance beyond their numbers (Kim 2003). Koreans played a vital role in the liberation of Manchuria, the civil war (1946-1949) and the Korean War (the 'Resist-America and Aid-Korea’ campaign) (Choi 2001; Kim 2003; Lee 1986). The Yanbian Korean Autonomous Prefecture is a strategically important border region adjoining the politically sensitive Korean Peninsula and Russia. Like some other minorities, such as the Kazaks, Russians and Mongols, Koreans in Yanbian maintain close relationships with their ethnic cousins in North Korea and South Korea, on the other side of the border (Lin 1997). In recent years, the contacts between ethnic Koreans in China and Koreans in the Peninsula involve the existence of the Korean community in Northeast China which becomes places for fugitives from North Korea and the potentially political link with the South Korean government or several nationalistic groups in South Korea (Choi 2001; Kim 2003). However, the contacts hardly cause any form of unrest, and Koreans keep intact their belief in the superiority of the communist party and its socialist system (Lee 1986; Mackerras 1994; Olivier 1993; Zhou 2000). The Chinese government has been watching 
these political contacts closely and continues to label the Yanbian Korean Autonomous Prefecture as a model of 'national integration and progress', and to highlight the success of ethnic Koreans and their loyalty to the Chinese Communist Party (CCP) (Kim 2003). Korean language becomes a language of political power, and therefore a language that is motivated to learn.

The power of minority communities' political will alone can go only so far in establishing a strong legislative stance and other factors, especially economy, have a strong effect. How the legislation is enforced and in what language community members actually develop their literacy are now essentially shaped by economic motivations (Zhou 2005). During the reform period since the end of 1970s, China's economic rationale for literacy has motivated legislation to define Korean language as functional. Prior to Korean immigration in a large scale in the nineteenth century, the northeastern China was largely uncultivated land (Piao 1990). Ethnic Koreans succeeded in reclaiming the land by cultivating rice paddies (Choi 2001). In contemporary China, Korean is coming to be seen as a language of economic power as China embraces globalization and the market economy spreads deeper into agricultural and pastoral minority communities. During the reform period, the increasing contacts with North and South Koreans promote border trade between China and North Korea around the Korean regions in China and South Korean direct investment in China with ethnic Koreans as the middle-men, due to ethnic and linguistic ties (Choi 2001; Kim 2003; Ma 2004). With the increased economic and social capital resources over time, ethnic Koreans’ intellectual capital within educational 
institutions helps to reassert a higher status of Korean language. The Korean language with its economical value is a key symbol of participation into business contacts with South Koreans (Choi 2001; Kim 2003). This article is intended to examine how a group of Korean students employ Chinese and Korean languages to achieve self-empowerment in a bilingual Korean school in Northeast China. Through examining the Korean students' language attitude and practice within the multiethnic school context, this article seeks to contribute to the literature that critically examines the issues of language and power. The research results indicate that both Chinese language and Korean language, with their political and economical power in China's reform period are vital for ethnic Koreans' adaptation to China's market economy and the increasing significance of transnationlism at a time of transition and change.

\section{Research methodology}

Data was collected from an ethnographic research on a group of 26 ethnic Korean students at the time of this study (September 2006 - January 2007), who were participating at two fourth-grade and sixth-grade classes respectively in a bilingual Korean school, the author called FLK School in Liaoning Province (one northeastern province). All ethnographies involve participant observation in the sense that it constitutes ‘a mode of being-in-the-world characteristic of researchers' (Hammersley and Atkinson 1983: 249), even though the degree of participation may vary. I took the participant-as-observer role that had the advantage of allowing me to penetrate social 
situations in order to establish relationships with the informants so that some understandings of their worlds might be achieved. I observed as well as participated (e.g. taking substitution classes or assistant role when it was needed) in situations. I made no secret of the investigation and made it known that the overriding interest was to observe and research. The role provided me with the freedom to go wherever the action was that was relevant to the informants (Burgess 1984). I strived to balance involvement with detachment and closeness with distance in order not to influence or be influenced by the research context. In addition to observing in the classroom, I also accompanied the informants to recess, playground, and school assemblies whenever possible. The goal during most of the observation time was to be a silent, unobtrusive observer. During lunch, recess, and break times in the classroom, however, my interactions with the informants were probably much more informal and participatory in nature. Over the period of five-month fieldwork, each numbered informant was interviewed once in order to obtain a series of deep insights into their language attitude and practice. The basic interview questions were focused on how these students constructed their attitude toward both Chinese and Korean languages, and how their language attitude impacted their language practice in daily school life. Individual interview took place in the school meeting room. The length of each interview ranged from one to two hours. Each interview was audio-taped and all tapes were transcribed. Interviews were supplemented by informal, natural conversations with the Korean informants, other classmates, academic teachers and parents/guardians involved. By giving young children a voice, it 
was a new experience for the author to be on the receiving end of the power differential between children and adults, and to focus on children as social agents who created the production and reproduction of childhood (Corsaro 1997).

\section{Bilingual education among ethnic Koreans in China and FLK School especially}

Zhou (2000) categorizes 128 distinct languages spoken among China’s minorities (Sun, Hu and Huang 2007) into three types: (1) minority languages with functional writing systems broadly used before 1949 have had regular bilingual education since 1949 including Mongolian, Korean, Tibetan, Uygur and Kazak; (2) those minority languages with functional writing systems narrowly used before 1949 have had occasional bilingual education since 1949 such as Dai, Jingpo, Lisu, and Lahu so on; and (3) those without functional writing systems before 1949 have had limited or no bilingual education since then such as Dong, Yao, Tujia, Tatar and She so on. In comparison with other languages, bilingual education for ethnic Koreans is more or less unique in its accomplishments. Korean educational success in China, for the last few decades, has been achieved mainly through the Mandarin and Korean bilingual education with an emphasis on Korean language as the medium of instruction in bilingual Korean schools (Ma 2004; Zhou 2000). The majority of Koreans, who represent China's thirteenth largest non-Han nationality ${ }^{1}$, are perceived as 'literate bilinguals' ${ }^{2}$, which are in sharp contrast with other minority groups in China (Guan 2001; Zhou 2000). In the mid-1980s the Chinese government began to implement bilingual education (Mandarin and minority 
language). There are two types of schools in the Korean concentrated regions: one is Korean and the other is Chinese. In Korean schools, students are given options to be educated and tested in their own language (Ma 2004). Korean is the medium of instruction and Chinese is taught as a subject. The Yanbian Korean Autonomous Prefecture Education Guideline promulgated in 1985 regulates that Korean schools must promote the transmission of Korean culture and traditions, especially Korean language. There is a long-term history for the Korean language teaching from Korean primary to higher schools. Originally, Korean language course was called 'yanwen' in 1946. Then it was called 'chaoxian yu’ in 1951, ‘chaoxianzu yuwen' in 1959, 'chaoxian yuwen' in 1963, 'yuwen' in 1969, and 'chaoxian yuwen' in 1972. In bilingual Korean schools, the Chinese language teaching originally started from year one of junior-secondary education in 1948. In 1951, it was taught from the fifth-year in primary education and third-year in 1956. In 1993, Korean schools started teaching Chinese language since the first year of primary education. The number of Chinese characters needed for primary students has increased from 1300 to 2200/2500 in 2002 (1800/2000 for written literacy). The bilingual program in Yanbian is often commended as the most successful example of China's bilingual education (Ma 2004).

FLK School was a twelve-year bilingual Korean school composed of three-year pre-school and nine-year compulsory education. At FLK, the Korean language was taught as a main subject and functioned as a main medium of instruction. All subjects were delivered in Korean, with the exception of those related to the Chinese and English 
languages and literature. FLK School was special to offer Chinese language studies as a main subject from the beginning of pre-school education. The Chinese language was also adopted as the medium of instruction for both Chinese and English subjects. At FLK, the curriculum was almost exclusively the translated version of standard textbooks except for the Chinese and Korean language textbooks. FLK gave the equal attention to Korean and Chinese, each of which accounted for $17.14 \%$ of the curriculum load. At the time of my research, FLK School was using the language textbooks which were published by Yanbian Education Publishing House. According to the teachers, the Chinese language textbooks were two grades lower than the textbooks used in Han schools. The Korean language textbooks were published according to the proficiency of students in Korean language in Yanbian, which were difficult for Korean students at FLK with a limited competency in Korean language.

\section{Korean students' language attitude and practice}

The language one individual uses is designated by one's relational position in one social context/field. Dominant uses of language reinforce structured differences in social power and prestige among groups. Linguistic interactions are therefore manifestations of the individuals' respective positions in the hierarchy of FLK School. The group of Korean students (19 out of 26) in this research tended to see themselves as half Han and half Korean. One student (Interviewee 12) said this: 
My mama is Korean, but my baba is half Han, half Korean because he is not only able to speak Chinese, also able to speak Korean. My mama...can’t speak Chinese well. She always responds to me in Korean when I speak with her. I can speak Korean and Chinese. I think...I am half Han, half Korean too just like my baba.

Educational aspirations that motivate children and youth to strive for educational success are shaped by the expectations of significant others, notably, parents, teachers, and peers (Campbell 1983; Davies and Kandel 1981; Hauser, Tsai and Sewell 1983). The Korean parents generally had positive attitudes toward Chinese and Korean language studies, which strongly influenced the learning motivations of their children. Most of the Korean students (24 out of 26) came from families which had the close connections with the South Korean community. The connections formed special ethnic capital for the students than other Korean students. The Korean students refused to align their experiences with those of other Koreans, while at the same time distinguishing themselves from pure Han majority. They asserted that their identities were the combination of their Koreanness and Hanness. The identification with half Han and half Korean, for them represented their superiority in both Korean and Chinese languages and free transition between the two worlds. China's market economy and increased business contacts with South Koreans contributed to the informants' understanding that Chinese and Korean memberships were strategically valuable. A Chinese identity coupled with a Korean one, connoted power and privilege. According to one student (Interviewee 2): 
I am not pure Korean, not pure Chinese. I can speak both Korean and Chinese. I feel that there are two worlds in my life: one is Korean and the other is Chinese. I enjoy being half Korean and half Han, which makes me comfortable to communicate with both Koreans and Han people.

The students generally recognized the advantages of half Han and half Korean identity for upward social mobility and linked them to their language attitudes. They affirmed the values of bilingualism and were developing characteristics as transnationals. This led to the importance of transnationalism which was a fundamental concept in regards to their language attitude. They generally tended to master as many languages as possible in order to transmit smoothly between the different worlds under the global context. As one student (Interviewee 6) remarked:

I have to learn Korean better because I would like to study in South Korea for college education. However, it is also important for me to master Chinese. Being competent in both languages is necessary in future.

They expressed a positive sense of Korean language, and held a positive attitude toward Chinese language as well. Their vision of upward social mobility was linked to an emphasis on Korean and Chinese language studies at FLK. According to one student (Interviewee 22): 
I feel like it's important to speak good Chinese. I want to go to university, prestigious university. I would like to find a well-paid job in a big cross-national company. I have to be fluent in English. Otherwise, I can’t have a bright future. I like English, Chinese and Korean languages. All of them are very important.

Their language perspective was also largely influenced by their teachers. According to the Korean students, their teachers generally highlighted the link between the rapid development of China's economy in the global world and ethnic Koreans' upward socioeconomic mobility. All the Korean students highlighted the importance of being able to work in the international companies with their competency in Chinese, Korean and English languages.

This orientation had an impact on their language practice in daily school life. The group of Korean students accepted the powerful currents of both Chinese and Korean memberships which were of great value in the world economy (Kibria 2002). They thus used both Korean and Chinese in daily communication and struggled to be involved in extracurricular activities and out-of-school classes in both Korean and Chinese language studies. Their language practice attempted to earn the respect of other students and to move up the social ladder at FLK School. There was one competitive and achievement-oriented social climate at FLK. Much school work at FLK from a very early age involved competition and comparison with others, and both teachers and students came to a sense of their worth in contrast to the rest of the group. The organizational 
structure of school through tracking and ranking breaks down the school along not only the line of academic achievement, but also the line of ethnicity. At the beginning of the autumn term 2006-07 when the fieldwork was undertaken, there were 327 students enrolled at FLK, which were composed of $83 \%$ Korean and 17\% non-Korean including Han, Manchu and Mango who were enrolled as 'Han'. The non-Korean students at FLK were collectively labeled as educationally successful, even though the students represented heterogeneity in academic attainments. The 'Han' students labeled as 'successful' became one potential source of the disadvantaged positions among Korean students at FLK. Academic achievement is probably the most important way other students can gain status (Lee 1996). For the students, their relatively higher academic attainment helped to affirm their positive self-identity. With the competency in Korean and Chinese languages, they felt empowered to achieve the advantageous position at FLK. Some of them spoke Korean to Korean students while speaking Chinese to non-Korean students. Some tended to speak Chinese with some Korean words or speak Korean with some Chinese words in their sentences as the 'code-switch' in conversation, according to the students. The language practice helped to keep the students in the higher status among peers. These students generally believed that they were able to transition smoothly from home to school, from Korean community to mainstream Chinese society. They held superior self-image as exemplars of success. This self-affirmation suggested a kind of self-evident superiority in comparison with both Korean and Han students. One student (Interviewee 13) commented: 
My mama said to me that I would not be able to learn Korean if I attended Han school. Then since I attend Korean school, I know more knowledge than Han students. And I am competent in Chinese. Thus I am in an advantageous position when I compete with Han and Korean counterparts.

\section{Conclusion: Bilingualism and transnationalism for ethnic minorities in China}

In the global era, ethnic minority students learning in these and other settings are more likely than in any previous generation in human history to face a school life within a bilingual or even trilingual language environment. The increased importance of transnationalism and bilingualism in new market economy emphasizes the role of Korean and Chinese languages in education for ethnic Koreans in China. The Korean students in this research constituted a special part of the study in language and power among China's ethnic minorities. Their attitude toward Chinese and Korean language acquisition and bilingual language practice in daily school life indicated the linkage between the bilingual acquisition and the process of empowerment in the academic hierarchy of the Korean school. The students universally committed to a positive attitude toward Chinese and Korean language studies and practiced a mixture of Korean and Chinese in school. This reflected their willingness of involvement into the mainstream and upward mobility and placed emphasis on intercultural interaction and transnationalism for benefits in increased business contacts with South Korea. 
It is clear from many studies (Baker 1993; Harrell and Erzi 1999), the language policies in education of multiracial or multiethnic countries tend to lead to what Skutnabb-Kangas and Phillipson (1995) have called 'linguistic genocide'. There is a lot of evidence that learning, particularly literacy development, is easier and more effective in the mother tongue/first language. As existing knowledge forms the basis of new knowledge learning, it will be logical to learn through the mother tongue. However, the use of mother language becomes a part of the disempowerment process. In its mildest form, this refers to what is called transitional or subtractive bilingualism such as the use of the mother tongue for initial literacy, usually for several years and its gradual or abrupt replacement by the dominant or official language as the language of teaching. For example, there are the increasing disadvantages Korean language teaching faces in China's reform period since the end of 1970s including (1) the decreasing Korean student intake; (2) the increased number of Korean students coming from problem families (e.g. Danqin: Single-parent family or Wuqin: living without parents), which lack necessary educational qualifications or are physically absent from family education; (3) the shortage of funding; and (4) the shortage of qualified Korean teachers (Gao 2009; Jin 2006; Lee 1986; Li 2006; Olivier 1993; Piao 2006; Zheng 2006). More and more Korean parents send their children to Han schools instead of sub-standard quality of bilingual Korean schools (Lee 1986; Olivier 1993). The overall effect of the monolingual habitus, from which all such policies stem, has been that language minorities have had to accept that they will be educated in a second or third language for most of their lives. 
Nevertheless, the profound forces of globalization with the accelerating flow of goods, people, data and information across national borders are lending growing weight to the conducting of a major dialogue on how education policy must manage difference within the context of bilingualism and multiculturalism (Suárez-Orozco and Qin-Hilliard 2004). The theory of language and power is concerned with theories of linguistic rights (Kymlicka and Patten 2003; May 2003) and multicultural citizenship (Churchill 1986; Gagnon and Pagé 1999; Kymlicka 1995). As extended to encompass multiculturalism, language power recognizes the linguistic rights of nations within states and the representational rights of poly-ethnic groups (Kymlicka 1995). It generally recognizes the importance of language to situate oneself culturally as having rights of cultural identity, and to position oneself as having rights of inclusion and participation into mainstream society. The ability to speak mainstream language is a key determinant that allows members of a minority group to share state and market resources with fellow Han citizens (Shih 2002). In comparison with mainstream language, a few minorities such as Korean, Dai and Jinpo whose languages also become cross-border languages for business contacts with neighboring regions (Shih 2002). However, globalization does not empower every minority language in China. For some ethnic groups whose languages are not popular, production and life frequently run into difficulties (Shih 2002). However, the ethnic language as the first language is a key symbol of ethnic identity, and an expression of one’s cultural and ethnic affiliation. Tové Skutnabb-Kangas (2000) in a discussion of the relationship between mother tongues and ethnic identities points out that people's 
ethnicity and languages can become positive forces and strengths that can help to empower them. The support and maintenance of languages of origin would permit language minority groups within the current global migration pattern, to maintain valued transcultural/transnational elements for their linguistic and cultural rights (Banks 2004; Hoerder, Hébert and Schmitt 2005). Whether ethnic minority students in China should be provided with education through mother tongue or whether Chinese teaching should be paid more attention in China's market economy poses more questions than answers to policy makers. However, the findings that both Chinese and Korean languages hold important economically and politically functional power have strong implications for the curriculum design and relevant policy initiations. With the increasing importance of multilingualism and multiculturalism, it is clear that language teaching among ethnic minorities within globalization needs an alteration of government priorities including multi-linguistic and multicultural themes in curriculum and teaching practices. 


\section{Notes}

1. The Constitution adopted in 1982 defines the People's Republic of China as a 'unitary multi-national state' (tongyide duominzu guojia) composed of the people of all its 56 nationalities (minzu) with a total population of 1.30628 billion (NBSC 2005). The majority of China's population belongs to the Han Chinese (90.56\%), whereas the 55 officially recognized minority nationalities account for about 9.44\% of the total population (NBSC 2005). There are also 1,072,642 people belonging to unspecified and unclassified minorities, $0.8 \%$ of the total population, according to the fifth national census in 2000 .

2. According to China's ethnic statistical yearbook (2005), while the percentage of college completion is 3.73 among total population, and 0.0009 among total minority, the percentage among Korean nationality is 8.38 . The illiteracy rate is 9.08 among total population, and 14.54 among total minority, whereas the rate is 2.86 among ethnic Koreans. 


\section{Notes on contributor}

GAO Fang is a Post-doctoral fellow in the Centre for Advancement of Chinese Language Education and

Research in the Faculty of Education, University of Hong Kong. She graduated from Ph.D. program in

Education at the University of Hong Kong. Her Ph.D. dissertation examines the schooling experiences of Korean students behind the model minority stereotype. 


\section{References}

Baker, C. 1993. Foundations of bilingual education and bilingualism. Clevedon (UK): Multilingual Matters.

Banks, J. A. (Ed.) 2004. Diversity and citizenship education: global perspectives. San Francisco, CA: John Wiley \& Sons, Jossey-Bass.

Bourdieu, P. 1991. Language and Symbolic Power. Cambridge: Polity Press.

Burgess, R. G. 1984. In the field. London: Routledge.

Campbell, R. T. 1983. Status attainment research: End of the beginning or beginning of the end? Sociology of Education 56: 47-62.

Choi, W. G. 2001. The Korean minority in China: The change of its identity. DEVELOPMENT AND SOCIETY 30: 119-141.

Churchill, S. 1986. The education of linguistic and cultural minorities in the OECD countries. Clevedon, Avon: Multilingual Matters.

Corsaro, W. A. 1997. The sociology of childhood. London: Sage.

Davies, M., and Kandel, D. B. 1981. Parental and peer influences on adolescents' educational plans: Some further evidence. American Journal of Sociology 87: 363-387.

Fei, X. T. 1991. Zhonghua minzu yanjiu xin tance [New Explorations in China's Ethnic Studies]. Beijing: Chinese Academy of Social Sciences Publishing House. 
Foucault, M. 1980. Power/knowledge: Selected interviews and other writings, 1972-1977

(C. Gordon, L. Marshall, J. Mepham \& K. Soper, Trans.). Brighton, Sussex: Harvester Press.

Gagnon, F., and Pagé, M. 1999. Conceptual framework for the analysis of citizenship in liberal democracies. Vol. 1: Conceptual framework and analysis. Vol. 2: Approaches to the analysis of citizenship in six liberal democracies. Report SRA-366. Ottawa, Department of Canadian Heritage.

Gao, F. 2009. Challenges of discourses on "model minority" and "South Korean wind" for ethnic Koreans' schooling in Northeast China. Diaspora, Indigenous, and Minority Education 3, no. 2: 119-130.

Guan, X. Q. 2001. Chaoxianzu shuangyu xianxiang chengyinlun [Causes of Korean bilingual education]. Beijing: Minzu chubanshe.

Hammersley, M., and Atkinson P. 1983. Ethnography: Principles in practice $\left(1^{\text {st }}\right)$. London: Tavistock.

Harrell, S., and Erzi, M. 1999. Folk theories of success: Where Han aren't always the best. In China's national minority education: Culture, schooling and development, ed. G. A. Postiglione., 213-241. New York: Falmer Press.

Hauser, R. M., Tsai, S. L., and Sewell, W. H. 1983. A model of stratification with response: Error in social and psychological variables. Sociology of Education 56: 20-46. 
Hayford, C. W. 1987. Literacy movements in modern China. In National literacy campaigns: Historical and comparative perspectives, ed. R. F. Arnove and H. J. Graff., 147-71. New York and London: Plenum.

Hoerder, D., Hébert, Y., and Schmitt, I. (Eds.) 2005. Negotiating transcultural lives: Belongings and social capital among youth in comparative perspective. Göttingen: V \& R Unipress.

Iredale, R., et al. 2001. Contemporary minority migration, education and ethnicity in China. Cheltenham, UK: Edward Elgar.

Jin, Y. H. 2006. Kaichuang zhiliangjia tesede yanbian chaoxianzu jiaoyu fazhan zhilu: Yanbianzhou chaoxianzu jiaoyu fazhan qushi yanjiu, [Establishing the development of Yanbian Korean education with quality and characterization: Research on Yanbian Korean education development]. Paper presented at the Korean Chinese Education Forum (1906-2006), August 17-19, in Yanbian University, China.

Kibria, N. 2002. Becoming Asian American: Second-generation Chinese and Korean American identities. Baltimore: The Johns Hopkins University Press.

Kim, S. J. 2003. The economic status and role of ethnic Koreans in China. In The Korean diaspora in the world economy, ed. C. F. Bergsten and I. Choi. Washington, DC: Institute for International Economics.

Kymlicka, W. 1995. Multicultural citizenship: A liberal theory of minority rights. Oxford: Oxford University Press. 
Kymlicka, W., and Patten, A. (Eds.) 2003. Language rights and political theory. Oxford: Clarendon Press.

Lee, C. J. 1986. China's Korean minority: The politics of ethnic education. Boulder: Westview Press.

Lee, S. J. 1996. Unraveling the “model minority” stereotype: Listening to Asian American youth. New York: Teachers College, Columbia University.

Li, Z. T. 2006. Guance minzu zhengce fazhan chaoxianzu jiaoyu: Shenyangshi chaoxianzu jiaoyude “zuotian”, “jintian”, “mintian”, [Implementing ethnic policy, and developing Korean education: "Past", "present, and "future" of Korean education in Shenyang]. Paper presented at the Korean Chinese Education Forum (1906-2006), August 17-19, in Yanbian University, China.

Lin, J. 1997. Policies and practices of bilingual education for the minorities in China. Journal of Multilingual and Multicultural Development 18, no. 3: 193-205.

Ma, C. H. 2004. Language practice and identity of Korean-Chinese bilinguals in Yanji. PhD diss., Michigan State University.

Mackerras, C. 1994. China's minorities: Integration and modernization in the twentieth century. Hong Kong: Oxford University Press.

May, S. 2003. Misconceiving minority language rights: Implications for liberal political theory. In Language rights and political theory, ed. Kymlicka, W. and Patten, A., 123-152. Oxford: Clarendon Press.

NBSC. 2005. China statistical yearbook. Beijing: China Statistical Press. 
Olivier, B. V. 1993. The implementation of China's nationality policy in the northeastern provinces. San Francisco: Mellen Research University Press.

Piao, C. Y. 1990. The history of Koreans in China and the Yanbian Korean Autonomous Prefecture. In Koreans in China, ed. D. S. Suh and E. J. Shultz., 44-77. Hawaii: The Center for Korean Studies, University of Hawaii.

Piao, W. Y. (2006). 21shiji zhishi jingji shidai chaoxianzu jichu jiaoyude zitaiyu keti, [Status quo and issues of Korean basic education in the 21 century knowledge economy]. Paper presented at the Korean Chinese Education Forum (1906-2006), August 17-19, in Yanbian University, China.

Postiglione, G. A. 2007. Ethnic minority policy in education: The educational challenge of harmonious multiculturalism. Paper presented at the Beijing Forum: The harmony of civilizations and prosperity for all diversity in the development of human civilization, in Beijing, China.

Shih, C. Y. 2002. Negotiating ethnicity in China: Citizenship as a response to the state. London and New York: Routledge.

Skutnabb-Kangas, T. 2000. Linguistic genocide in education - or worldwide diversity and human rights? Mahwah, N.J.: Lawrence Erlbaum.

Skutnabb-Kangas, T., and Phillipson, R (Eds.). 1995. Linguistic human rights: Overcoming linguistic discrimination. Berlin/New York: Mouton de Gruyter.

Suárez-Orozco, M. M., and Qin-Hilliard, D. B. (Eds.). 2004. Globalization: Culture and education in the new millennium. Berkeley: University of California Press. 
Sun, H. K., Hu, Z. Y., and Huang, X. 2007. Zhongguo de yuyan [The languages of China]. Beijing: The Commercial Press.

Tollefson, J. 1990. Planning language, planning inequality. London: Longman.

Zheng, X. Z. 2006. Luelun chaoxianzu jiaoyu fazhan xianzhuang jiqi duice, [The preliminary discussion about the status quo and strategies of Korean education development]. Paper presented at the Korean Chinese Education Forum (1906-2006), August 17-19, in Yanbian University, China.

Zhou, M. L. 2000. Language attitudes of two contrasting ethnic minority nationalities in China: The 'model' Koreans and the 'rebellious' Tibetans. International Journal of the Sociology of Language 146: 1-20.

Zhou, M. L. 2005. Legislating literacy for linguistic and ethnic minorities in contemporary China. Current Issues in Language Planning 6, no. 2, 102-121. 